\title{
Virtual Reality Technology as an Didactical and Pedagogical Resource in Distance Education for Professional Training
}

\author{
Elomar Christina Vieira Castilho Barilli \\ Additional information is available at the end of the chapter
}

http://dx.doi.org/10.5772/50625

\section{Introduction}

When we read a good book, soon our imagination takes us to amazing situations: in an instant we are transported to sumptuous castles... in another we are piloting huge spaceships or traveling inside the human body. More than this, we sometimes ask ourselves how it would be like if fiction became reality and we could fly through clouds or explore subsea mountain ranges?

Today, what seemed impossible 'can' already be done through a technology that combined knowledge from many different domains (Anatomy, Biology, Biochemistry, Physics, Computer Sciences, Graphic Design, etc.) into one single multi-disciplinary entity capable of providing non-specialized users virtual worlds that simulate reality with a wealth of detail, giving them even the subtlest of sensations through its output devices. As regards the 'real world', in some areas like Health, there is no room for rehearsals and much less for errors. Technical mastery can mean the difference between life and death.

Virtual Reality (VR) involves revolutionary technologies in the development of applications, as a result of the new possibilities it gives to the man-content interface, via multi-sensorial devices, navigation in three-dimensional spaces, immersion in the context of the application and real time interaction.

Costa et al (2001) state that VR is the most natural of the Man-Computer Interfaces (MCI) due to its potential for multi-sensorial interaction. This means that, through this technology, the computer-generated virtual environment can provide the user with interaction with the use of senses (sight, hearing, touch and, more recently, smell). Apart from that, due to the manipulation of objects and movement in the environment happening in real time, the 
authors believe that the big advantage of this interface lies in the fact that experiences occurring in the physical world can be intuitively changed in the virtual world.

As regards Education, it should be pointed that the increase in the use of Information and Communication Technologies (ICTs) requires the construction of a new pedagogical model in which the educational activities for the apprehending of (re)constructed knowledge promote the use of its resources to assist human beings to overcome physical, social, and cultural barriers universally.

Beyond the factors that are connected only to scope and/or scale, Education seeks more than expanding access opportunities. The challenge is to diversify the ways to present and represent the organized bodies of knowledge to foster the construction of meanings for cognitive appropriation.

Its goal is to enable the student to reflect on his or her own needs and potentials, contributing to the development of a critical consciousness about the contents that are relevant for the educational process, allowing them to decide when and how to use the knowledge acquired.

The integration of these factors make Distance Education (DE) one of the most promising educational alternatives, for its capacity to transcend time and space and assist in the development of an organized stance while providing human interaction and favoring cooperative learning.

In this context, the use of VR technology can contribute to motivate the learning experience through the 'experiencing of real phenomena', being free of the consequences the real world imposes. Thus, new educational possibilities can arise from the VR-DE integration.

At the same time, Colleges and Universities are experiencing a special moment, resulting from contemporary social demands: to prepare future professionals for a highly competitive job market, which requires workers with special profiles, well-defined technical competencies but, chiefly, capable of critically thinking about the daily phenomena of work and, with a generalist basis and knowledge, propose solutions to solve complex problems.

As a result, apart from technique and basic competencies (reading, understanding, interpreting, listening...), other highly-valued human competencies come to the fore (such as negotiating, getting to know the context of work, applying the method, sharing...,), as well as being adapted to the technological world people live in. Indeed, the creation of different technologies seems to emphasize its status as pre-requisite for the access to the possibilities of qualification for the job, through physical attendance to classes or in distance education.

In the field of professional training education the knowledge applied is multi-disciplinary and complex, and often requires visualization and manipulation. Thus, VR technology is a powerful ally to the 'from a distance' education proposal, capable of providing multiple educational opportunities. Together with it, the use of VRML (Virtual Modeling Language) enabled the use of its applications on the Internet, which contributes to the use of VR in education. Apart from the simulation of reality, after VRML its systems and applications became lighter and faster, an important feature in e-learning educational processes. 
VRML is a platform-independent language that describes and enables the creation of 3-D virtual environments on the Internet, where one can browse and visualize objects from different angles and interact with them, changing their characteristics if necessary. The immersion is not possible in VRML sites although they offer 3-D worlds, interactive and integrated with other worlds and Web links, giving them a flexible access nature (they can be accessed from notebooks, tablets, smartphones etc.).

The VRML environment can be written with a code produced in a word processor, describing the environment and the events associated with it, with no need of a compiler. The applications can then be produced with the use of commercially available editing software (Cosmo World, ISA and others), that will be interpreted by the browser with the assistance of a plug-in (http://www.cortona3-D.with/Products/Viewer/Cortona-3-DViewer.aspx). For more complex projects, however, 3-D modulators and graphics editors should be used as support tools.

Its execution is run from a link that, once decoded by the browser, loads a text file with the description of the environment and, after that, loads the textures. In other words, to open a Web address (URL) that contains a VRML document (.wrl extension). Once the browser detects the file type, a VRML visualizing plug-in enables the visualization and movement of the objects in the 3-D virtual world. From there on, the system is operated by the user.

The figure below shows a VR app for the Web where the student can rotate, and zoom the object in and out, apart from simulating different weighing operations and calibrations.

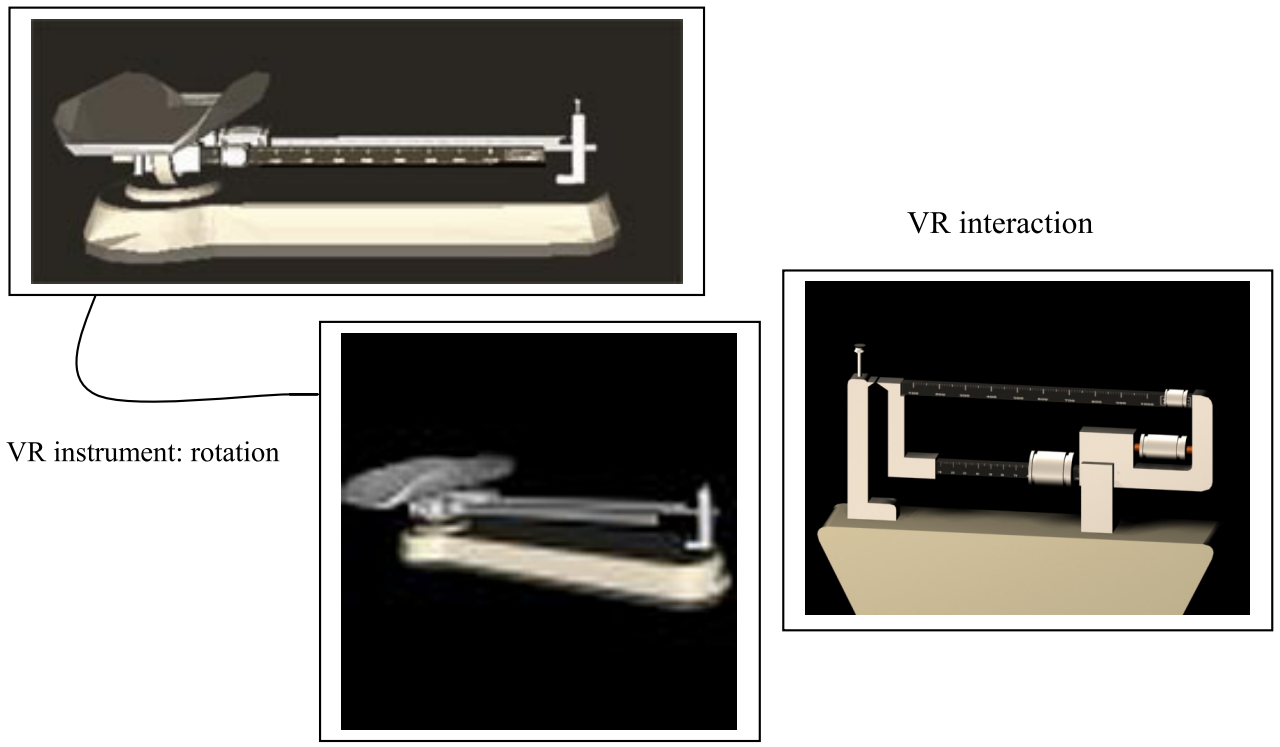

Figure 1. Distance Education Course on Food and Nutrition Inspection for Indigenous Health: Training in Anthropometrics (http://www.DE.fiocruz.br/course/index.cfm?cursoid=794) Distance Education Coordination of the Brazilian Public Health School - Fundação Oswaldo Cruz 


\section{Pedagogical or technological reference: Which one is more powerful?}

\subsection{Permanent professional training}

With the aim of demystifying the use of VR or any other technology (given that technology is not a panacea capable of solving the issues of education, but a resource to strengthen it) it should be noted that the theoretical-pedagogical reference is the element that determines the entire educational project the technology is inserted in.

According to Darsie (1999, p. 9), 'all the educational practice carries in it a theory of knowledge'. Thus, should the pedagogical orientation adopt "instructivism", which embraces an associationist and mechanistic epistemology (Neves and Damiani, 2006), the use of technological innovations will only reproduce traditional educational models supported on the pedagogy of memorization (mechanical learning), error and success.

On the contrary, that which is sought is the use of VR, with the implementation of construction processes that find identity with the theories of interaction-based constructivism and with dialectics, which bring as fundamental truths: 1) that all knowledge comes from social practice and returns to it; and 2) that knowledge is a collective undertaking, and cannot be produced in the loneliness of the subject (Vygotsky, 1984 apud Neves and Daminani, 2006). According to Beker (1993), authors considered as social constructivists such as Piaget, Freud, Vygotsky, Wallon, Luria, Baktin, and Freinet have the action of the student as a praxis in the medium of the learning process, as their common place, understanding 'praxis' as any intervention of human beings in society and on nature.

To the authors above, we can add to the theoretical premises that steer the learning processes to the autonomy, liberation, and citizenship of the student, via the dialogue.

DE can and should be considered as an educational modality that brings with it technology as a strategic resource that, if used 'rationally', can work as a mediating instrument between contents and learning. However, discussing the rational use of the technology in education requires a reflection on some points: 1) with physical presence or from a distance, the educational proposal is inserted in the field of Education and should therefore be subjected to its theoretical and methodological premises, that is, education with physical presence and $\mathrm{DE}$ are not different things that should be treated according to different theoretical references and therefore...; 2) the pedagogical reference should be the guiding element for the planning, definition of strategies, actions and resources (media). Thus..., 3) the means of communication are conditioned by the access parameters of the public that is the target of the educational proposal, and; 4) the teacher responsible for the pedagogical mediation (teaching), should get educational assistance to support one's actions.

The UNESCO's World Declaration on Higher Education in the 21 ${ }^{\text {st }}$ Century established essential elements, where we can find: the concern with social issues, the emphasis on fundamental values and the giving value to diversity in Education through the innovative use of educational methods that allow critical thinking, expansion, creativity, and growth opportunities through Distance Education. 
Based on these points, strategies for professional qualification currently include elements related to the theoretical principles of psychopedagogy, relating them to the construction of knowledge from experience (constructivism), resulting from human cooperation in a social context (social constructivism), observing the ways of teaching and learning that are provoked by the theories of Andragogy and significant learning.

Andragogy examines how adult students learn, incorporating to the educational project elements such as the needs of problem identification, analysis, decision-making, and autonomy. Significant Learning brings relevant context elements to the learning process, allowing the construction of sense (meaning) for the student.

As regards professional qualification education, the theoretical lines mentioned comply with the approach of Permanent Education (PE). PE is the concept in teaching/learning adopted by the Brazilian Health Sector, which recommends organic relations between teaching and the actions of the health services. PE starts at work, transforming everyday events into learning situations.

Teaching strategies attempt to take the student to identify the critical moments in the daily life at work and study them under the light of a theoretical set of references aimed at decision-making and towards a more effective action.

The goal of PE is therefore to qualify the work practices through education. In this conceptual scenario, the use of active learning methodologies seems to be the obvious choice, building teaching strategies that focus on provoking a reflection on real situations of the work context (case studies and problematic situations) to enable the student to reflect and question one's own reality.

In this context, the diversification of contents and the presentation of a simulation of external stimuli will certainly help motivate and enhance learning.

For Santos (2008),

[...] From the perspective of today's Cognitive Psychology, the human mind is regarded as a system that computes representations. The mind receives sensorial information from the world and generates representations about it. These mental representations are ways to intimately re-present the outside world (p.10).

VR acts here as a tool capable of meeting the educational needs in distance teaching contexts, as it entails different cognitive styles and sensations of the outside world. VR rises as a new interface generation where, using tridimensional representations that are closer to the reality of the user, it allows breaking the barrier of the screen, enabling natural interactions (Kirner and Siscouto, 2007, p.4)

From e-mail to the GPS, much has been discussed about the ways to provide distance education, its potential and limitations in a scenario of social and cultural diversity that rises from a proposal that goes beyond time and space: the role of the actors involved, the ways to construct and acquire knowledge... 
PE seeks to blend daily-life factors, using technology to unite people and, in the case of VR, to simulate situations as realistically as possible, bringing the learning experience to the concrete practice.

However, for the educational project can contribute and lead the students to conquer their place in the world with dignity, with quality in their survival and well-being, it is necessary that all available resources are used within the perspective of a rationale of citizenship for the construction of autonomy. It is not enough to educate for work; it is necessary to educate for life.

Following this reading, how would you answer the question asked by the title of this topic?

\section{The technology of Virtual Reality (VR)}

Since the summer of 1896, when Frenchman Joseph Nicéphore Niépce obtained the first photograph of the window of his house, Man has been attempting to move from the role of a passive spectator of whatever is presented by nature towards becoming an agent that culturally interferes in Nature (Barilli et al., 2011). From that moment on, Niépce opened the door to a vast array of possibilities offered by his intelligence, to quench his thirst in understanding the unknown, create and improve mechanisms, which put him on a constant search for innovation.

In the history of the Computer Sciences, VR was, until recently, rated as a new technology, because of its dependence on technological advances that were associated to the processing of computer systems and the standardization of equipment conceived for interaction. The latter can be considered an important element in the democratization of its use in different knowledge domains.

VR is the result of a long evolutionary process. The first VR applications appeared in the 1960s in the US military sector, due to the need to provide training to aircraft pilots. A virtual environment aimed at simulating real situations and risk factors, minimizing cost and, at the same time, raising safety and efficiency levels in training. Presently, the military industry still uses this technology, improving the presentation / interaction of its interfaces.

The advancement in communication technologies, as well as IT and computer technologies, however, broadened its use, allowing other knowledge domains to also benefit from it, simulating phenomena for domains such as the mining, oil, health and education sectors (amongst others).

The word virtual comes from the medieval Latin word virtualis, stemming from virtus, which means strength, power. In Scholastics ${ }^{1}$, virtual is that which exists in possibility and not in

\footnotetext{
${ }^{1}$ Scholastics represents the last period of Christian thinking that goes from the $9^{\text {th }}$ century to the end of the $16^{\text {th }}$ century, that is, the constitution of the sacred Roman barbarian empire at the end of the Middle Age that is usually marked by the discovery of America (1492). This period in Christian thinking is known as Scholastics as it was the branch of Philosophy taught in schools back then by the masters, known as a result as scholastics. The subjects taught in medieval schools were represented by the so-called Liberal Arts split into three subjects: Grammar, Rhetoric, Dialectics, and into four disciplines: Arithmetics, Geometry, Astronomy, and Music. Scholastics rises historically from the special development of Dialectics. (http://www.mundodosfilosofos.com.br/escolastica.htm
} 
the act. The virtual tends to get updated without having moved, however, to effective or formal materialization (the tree is virtually present in the seed). In strictly philosophical terms the virtual does not oppose to the real, but to the present. Virtuality and actuality are only two ways of being different' (Lévy, 1996, p. 15).

VR technology allowed that, apart from being an observer, Man became an explorer, interfering and modifying the elements of a virtual environment which, in real conditions would be inaccessible, in systems designed not only to mirror the real world but to represent all of its imaginative power. This characteristic places the student as an active agent in the learning process, vital condition for distance education.

The expression VIRTUAL REALITY appeared in the 1980s when Jaron Lamier (father of the data glove and presently a specialist with the MIT - Massachusetts Institute of Technology) felt the need to coin an expression that would set 'traditional' simulations apart from the virtual worlds he then developed (Braga, 2007; Vilela, 2006).

For Vilela (2006), VR 'consolidated itself due to the convergence of immersion and interactivity in the man-machine relation'. For this author, the constant search for the feeling of immersion (and interaction) in the virtual environment, as supported by VR, is responsible for its evolution.

There are several accepted definitions for VR. This is partly due to its interdisciplinary nature but also to its historical development.

VR is the 'generic' name that represents a technology through which the user can freely visualize, explore/manipulate, and interact with complex data in real time (Alves et al., 2011).

With the grouping of other concepts, one can say that VR is an advanced technical interface capable of providing the user a feeling of immersion (feeling of being in the environment), of browsing and interaction in a computer-generated synthetic tri-dimensional environment, using multi-sensorial channels.

The environments developed in VR have five elements that form its main characteristic (called 5 "Is"): Immersive, interactive, intuitive, illustrative, and intensive.

Thus, VR can be immersive or not. That which sets it apart is the use of physical technologies (supported by logical ordering technologies). The first type depends on input/output devices (helmets, gloves, and even projection rooms). The non-immersive one is based on the use of a monitor, mouse, or touch screen. These are simpler and have low cost and are ideal for distance education courses via the Web.

The image below shows a student browsing the contents of one of the distance education courses that uses VR on a monitor.

In order to intensify the feeling of immersion, a helmet and gloves can also be added, as well as sound (sound can create a feeling of movement and location). 


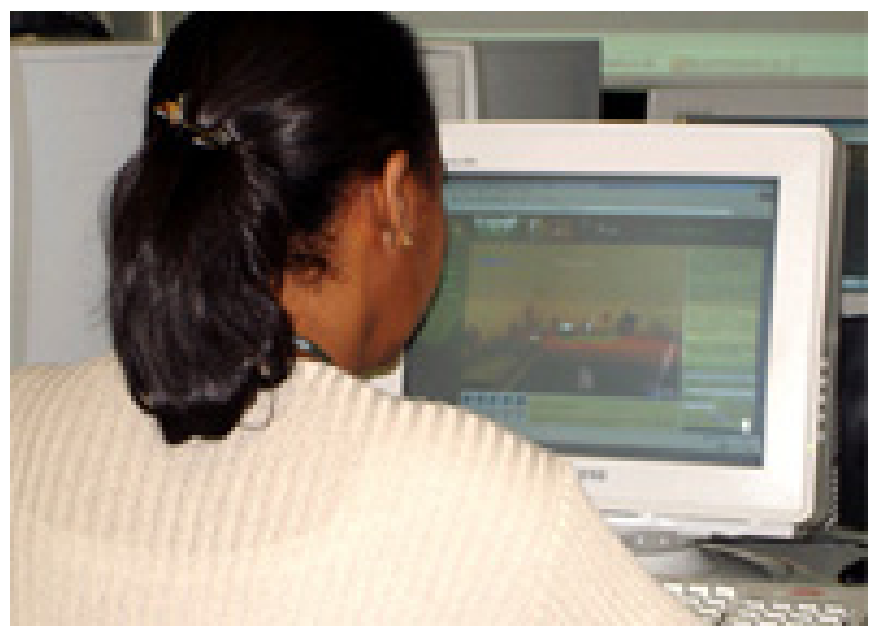

Figure 2. Monitor VR

Kirner and Sicouto $(2007$, p.92) state that a VR system can be synthetic (generated in real time), tri-dimensional, multi-sensorial, immersive, interactive, realistic (reproduction of real objects) and with presence. Therefore, we can consider it as a tri-dimensional graphical environment that integrates audio, generating in real time and that allows interactivity.

Audio-Visual Realism is the experience of uniting sight and hearing. Sensations of touch and strength (haptic devices) allow the system to be more realistic, minimizing, at the same time, its own presence (size and weight). These are the last devices, known as tactile interfaces and refer to the study of how to integrate the human sense of touch to a computer-generated world.

For Smith (2007), a problem displayed by VR systems is the lack of stimulation for the sense of touch. If an user tries to grab a virtual glass, for example, without a haptic device, it will not be possible to know whether the glass is in contact with the virtual hand. It is expected, in the short term, that studies on haptic feedback devices may supply this demand. Haptic devices can be further divided into: 1) tactile feedback - through which one feels shapes and textures. They are the devices that provide interaction with the nervous endings of the skin and that indicate heat levels and textures. The feeling of touch provides information on the surface geometry, its texture or temperature. It is largely used in virtual environments where the light levels are low or non-existent (sea floor, for example); and 2) force feedback or kinesthesia ${ }^{2}$ - through which one feels feedback forces and movement. They are devices that interact with the muscles and tendons, giving the user a feeling of application of force in the opposite direction. The feeling of force provides information on the weight of the object and its consistency. These devices are part especially of the robotic manipulators that push the user against the forces that correspond to the virtual environment.

\footnotetext{
${ }^{2}$ Kinesthesia - sense that perceives the position of the body, movement, force, weight and resistance through the movements of muscles and tendons.
} 
Immersive VR logically provides more possibilities for interaction and involvement. However, depending on the goals and possibilities, non-immersive VR can be a feasible choice, as it is easy for developers (there is no need for writing special drivers or doing very complex programming) and for users (can experience the virtual environments with simple hardware configuration settings and in any place).

VR systems also have the characteristic of uniting four basic ideas: immersion, interaction, presence, and involvement:

a. Immersion - Apart from the visual factor, the devices connected to the other senses also are important for the feeling of immersion, such as sound, automatic positioning of the person and of the movements of the head, force feedback controls, etc.;

b. Interaction - The idea of interaction is connected to the capability of the application to detect the inputs from the user and immediately change the virtual world and the actions in it (reactive capability). People are captivated by a good simulation in which one can see the scenes change in response to one's commands (this is the most striking characteristic in videogames);

c. Presence - obtained through multi-sensorial sensations (Costa, 2001);

d. Involvement - this idea links to the degree of motivation that drives the user to run a given activity. The involvement can be passive, such as reading a book or listening to good music, or active, in taking part in a game with other people. VR has potential for the two kinds of involvement when, apart from allowing the exploration, also provides user interaction with a dynamic virtual world

\subsection{VR systems}

1. Tele-presence (tele-operation, tele-robotics, tele-existence); this technology increases human and sensorial mobility and the capability of solving problems in a remote environment. In tele-presence, a robot is physically separated from its human operator, who carries out the operations that are executed by the robot at a distance, offering a sensorial feedback to the human operator. This causes the operator to have the feeling of being present in the remote environment. This system has been widely used in the medical area, allowing technical immersion in the undertaking of remote surgery procedures by specialists who work in large urban centers. The surgical procedures supported by tele-presence minimize the distortion inherent to the human hand, increasing the precision of the cuts.

2. Augmented Reality (AR) is the overlapping of computer-generated virtual objects in a real environment, using a technological device. It is considered that AR is a sub-group of the so-called mixed reality which is a blend of the real environment over the virtual environment as generated by the computer. They can be split into: a) Augmented Virtuality: there is a predominance of virtual elements in the real environment, and $b$ ) Augmented Reality: where the predominant elements are the real ones.

Taking advantage of the advances in mobile communication technology, a growth in Virtual Reality is observed for Mobile Computing or VR applications for mobile devices. This 
resource can provide Distance Education with yet another resource for the enhancement of Mobile-Learning or simply m-Learning. This includes smartphones and tablets due to their portability and ease of use.

VR systems are designed not only for reflecting the real world but to represent all the creative power of Man. Therefore, in its environments, the computer generates a simulation of a world that can be real or imaginary, using a graphical or text interface. For Distance Education (DE), second life environments are very much used as we shall see below.

\section{The use of virtual reality technology in education}

The human forms of apprehension are multi-mode in their nature (Treviranus, 2004) and, as regards the constructivist premises of learning, this means placing the student at the center of the learning process, giving her/him the tools necessary for this experience and appraisal, especially in the Sciences where the visualization/manipulation of tri-dimensional objects are important for learning, as already used in the teaching of geometry systems (Augmented Reality) (Lima et al., 2007, p.3 ) and Algebra, facilitating the understanding of abstract concepts.

In Statistics, in the work with multi-varied data, the analysis and interpretation can be done interactively in immersion systems (digital CAVE), allowing students to understand and manipulate complex data sets (Sawant, 2000).

One characteristic of this technology that interests education is its adaptation to different forms of learning, that is, cognitive styles. For people with problems to understand equations, theories, and principles, VR can be used to make this type of information concrete. For those with a taste for the visual and not the verbal, who prefer graphics and images rather than explanations and formulae, VR is again useful, especially because of the its highly visual aspect. As regards those that would rather learn through exploration instead of deduction, VR can enable a detailed analysis that would often have been impossible by other means. Finally, for those who learn better by actively interacting with the environment, instead of learning in a reflexive way, with thinking and introspection, VR environments can be highly interactive, allowing the direct manipulation of environment elements that respond to the actions of the user in real time.

Young (2000) states that the insertion of VR technology in DE contributes to increase the quality of the educational processes as the access to the own contents and communication of DE can be strengthened by a report of experiences had in real time. Apart from that, the socalled monitor VR contributes to the humanization of DE, as it allows the student the personal impression resulting from the selection of individual routes and the use of the elements of interaction, setting the number of times for manipulation and / or the time of permanence at the place in the virtual world that attracted one's attention the most.

There is no doubt that the advances and the appropriation of the Web by part of the society in the world have forced the domain of Education to think about new ways for distance Education. More than the ease of access to information, the education seeks to incorporate 
new manners of shared learning and in a networked way (to avoid the isolation characteristic of the 1990s).

The idea, as we have seen it, is not to reproduce the space of the classroom in the distance but to construct a new space for human communication and interaction for learning through the collective production of contents and bodies of knowledge.

The virtual classrooms of today have transcended the old bi-dimensional ones used in chats for a tri-dimensional model that is increasingly like that of the real world. The idea is to provide students with a realistic environment to reduce the distance and encourage peer cooperation.

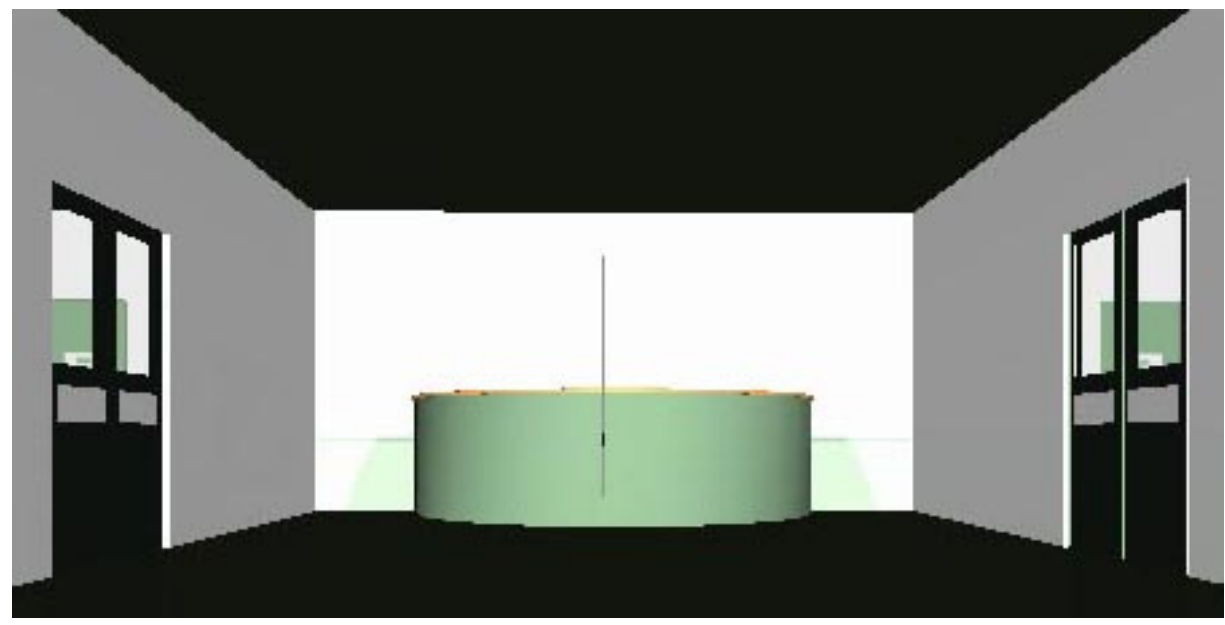

Figure 3. VR school

In Distance Education processes, the introduction of the technology is giving a new meaning to the role of students, teachers and the organizational ways of appropriation. When using VR technology, however, these changes gain greater magnitude as they allow experiences quite similar to the real world, where the members of learning community can relate between themselves (seeing, hearing, and touching) without never having been physically with one another.

There are several educational activities that already benefit from the use of VR. In the field of applications for the Health Sciences its use, dated from the 1990s, revolved around the field of Therapeutics. Now, the tri-dimensional and robotic models assist in bold plans for professional qualification: emergency rooms, surgical procedures and other activities linked to the promotion, care and protection of health.

As we have seen before, the inclusion of system resources depends of the characteristics of the target public, a fact that conditions the adjustment of VR for education. The figures below show a virtual environment based on VR for the Web, designed to contribute as a 
supplementary learning environment for the course to qualify professionals associated with the Distance Education Course on Food and Nutrition Inspection of the Brazilian Department of Health.
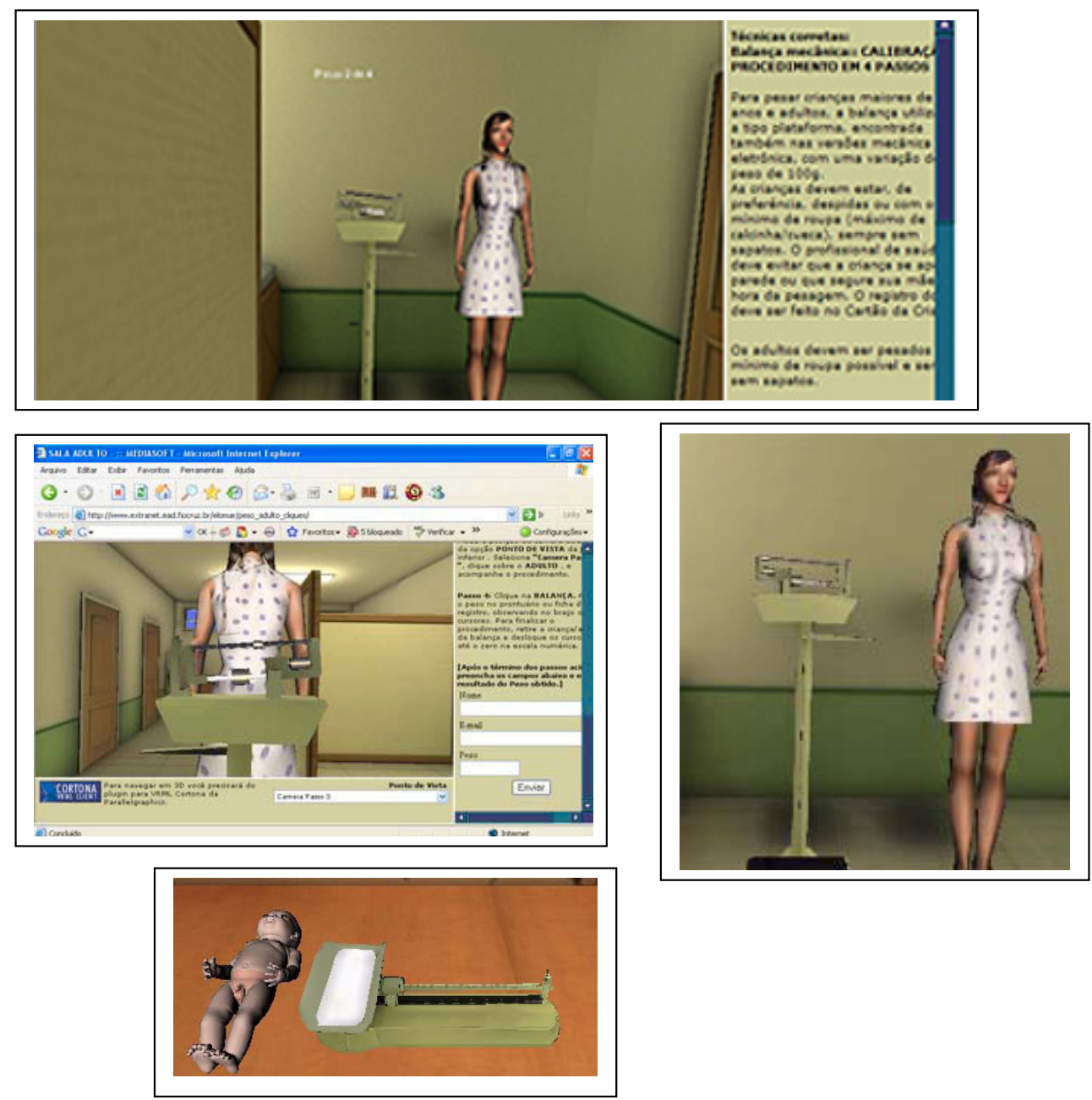

Figure 4. Virtual Learning Environment in VR technology: Course of the Food and Nutritional Surveillance System, Distance Education Coordination - Brazilian Public Health School -Oswaldo Cruz Foundation

Apart from the contents already discussed in the didactical materials of the course, the virtual environment was developed as a prototype to assist in the anthropometric qualification (weighing and measuring), as such data is the basis for the construction of interventions related to the control of nutrients for the Brazilian population. 
In pedagogical terms, the system offers the possibility of interaction with 3-D tools, procedure visualization and execution (scale calibration, patient positioning, result indication and readings), analysis and interpretation of a case study. Due to the fact that the instruction design of the course adopts the theoretical references of constructivism and Permanent Education, the answers to the exercises proposed and the study case are sent (via email) to the teacher that is asked to discuss them with the student, using the error (if any), as the starting point for the joint revision.

Other examples can be found in the oil \& gas industry (offshore) that are used to simulate in the digital CAVE learning situations in deep water and also to train naval industry engineers.

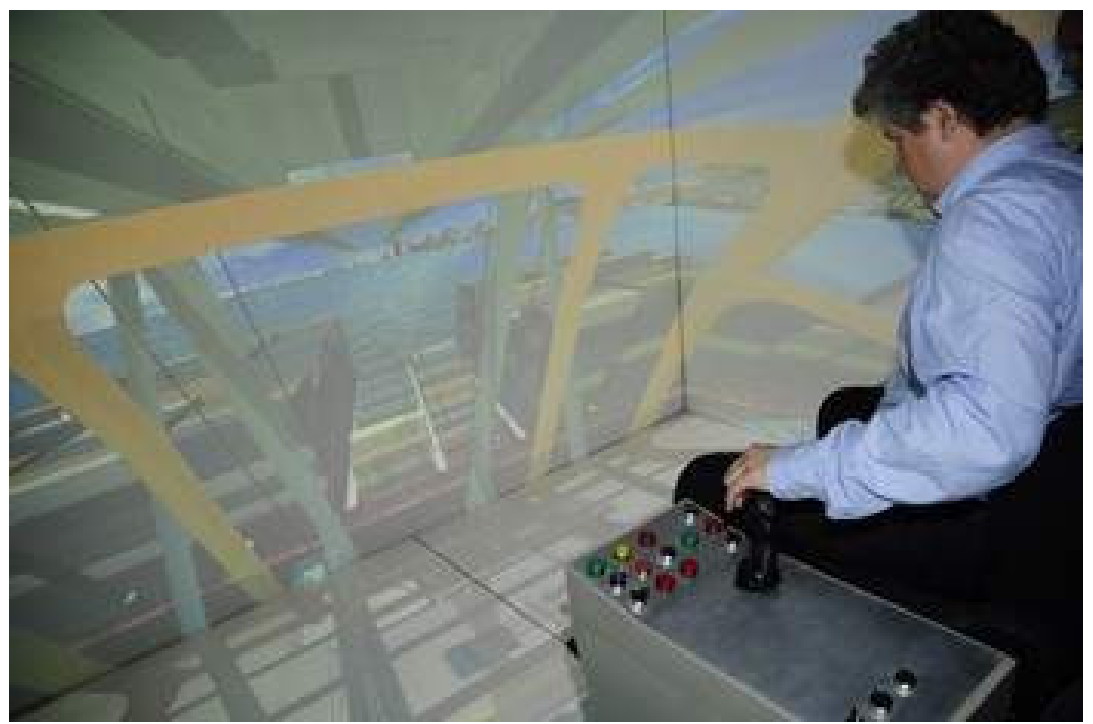

The simulators work with a replica of the cabin with all the active, integrated controls of a visualization system in digital CAVE. [Image: COPPE/UFRJ. Extracted from http://www.inovacaotecnologica.with.br/noticias/noticia.php?artigo=simulador-portuario

Figure 5. Port Simulator

Still as regards the use of VR in Distance Education, Second Life (SL) has been one of the systems most used. SL is a virtual tri-dimensional environment that simulates some real life aspects. It can be understood as a 'parallel environment' where an individual 'extends' one's real life, expanding one contact network in a virtual environment. As regards the educational context, SL applications have been used to widen the interaction amongst the learning communities where the students participate in distance academic events.

SL environments have therefore been considered as collaborative environments (AVCs Collaborative Virtual Environments) as the participants are simultaneously present in a world that simulates the real or the imaginary domain, and can interact with elements in real time. The communication is usually made via a conversation (chat) tool or as an audio 
or video conference. Each participant takes over an avatar that has one's physical characteristics (or not). However, the personal traits are evident.

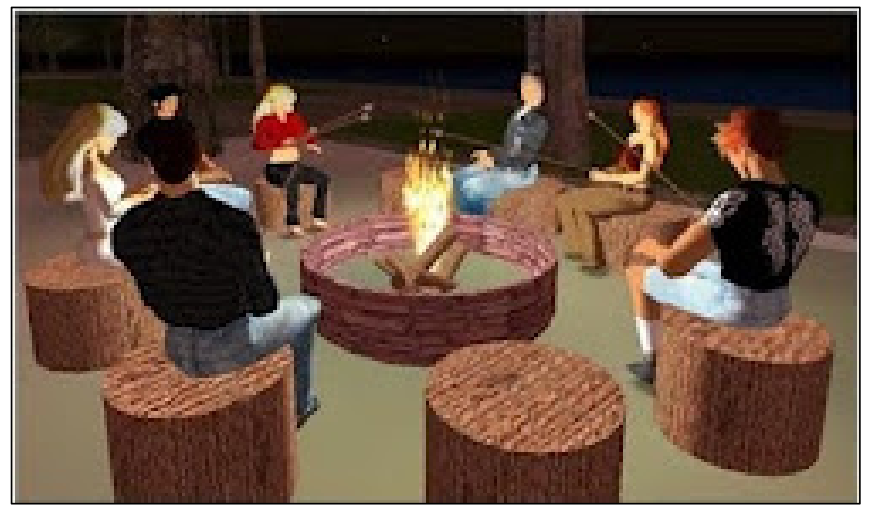

Figure 6. Second Life environment (JOVEAD 2011) $)^{3}$

Despite all the potential provided by the VR, it is important to concentrate the efforts in the search for its use, as well as for the technological apparatuses available as motivator elements of the reflection on the practice thus reaffirming that the technology, in itself, does not promote the education.

Finally, due to its characteristics VR has been considered as a technology that occupies a 'market' that is highly promising as it can be used in very profitable areas (entertaining, oil \& gas...). The reduction in dimension of the devices, coupled to processor speed has made this technology an object of investigation all over the world.

In the scientific field, however, it is expected that is seen as a multi-disciplinary approach, spanning involving knowledge of the areas of IT, Man-Computer Interfaces (tri-dimensional entity behavior, real-time interaction, etc.), Education, Psychology, amongst others, aimed at enhancing communication, rehabilitation, qualification... with the goal of having virtual learning contribute to the qualification of the real-world citizen.

\section{Author details}

Elomar Christina Vieira Castilho Barilli

Coordination of Knowledge Management. Area of Distance Education, Escola Nacional de Saúde Pública Sergio Arouca - Brazilian Public Health School, Fundação Oswaldo Cruz, Brazilian Department of Health, Brazil

${ }^{3}$ http://search.babylon.com/imageres.php?iu=http://3.bp.blogspot.com/35_qlYNVBsE/ThJ2YpXol8I/AAAAAAAAEnA/8bqkm12-8VI/s250/sla.bmp\&ir=http://explorandometaversos.blogspot.com/2011/07/apresentacao-de-trabalho-no-jovaed2011.html\&ig=http://t0.gstatic.com/images?q=tbn:ANd9GcQoBLYZNDwwFQWUZaJJkrRQ4iiLWsX-0HCYkNM9BvWHEeH9P95liP8RA\&h=146\&w=250\&q=jovead+second+life\&babsrc=SP_def 


\section{References}

Alves M.; Aghina A. C.; Mól C. A.J.; Celso L.; Nomiya D.; Cunha G. G.; Landau L.L.. Tangible Interfaces for Virtual Nuclear Power Plant Control Desks. Information and Communication Technologies Research Laboratory (LATEC/UFRJ), from the Federal University of Rio de Janeiro (UFRJ), in partnership with the Applied Virtual Reality Group (GRVa), from the Laboratory for Computational Methods in Engineering (LAMCE) from COPPE/UFRJ, 2011. Available from:

http://www.latec.ufrj.br/revistas/index.php?journal=realidadevirtual\&page=article\&op= view\&path $\% 5 \mathrm{~B} \% 5 \mathrm{D}=194$

Barilli E. C. V. C.; Ebecken N. F. F.; Cunha G. G.. The technology of virtual reality resource for formation in public health in the distance: an application for the learning of anthropometric procedures. Ciênc. saúde coletiva vol.16, supl.1, Rio de Janeiro, 2011.

Becker, F. Modelos Pedagógicos e Modelos Epistemológicos. Porto Alegre. Paixão de Aprender, No. 5:18-23, 1993.

Behar Patricia Alejandra. Modelos pedagógicos em educação a distância, Chapter 1, 2009. http://downloads.artmed.com.br/public/B/BEHAR_Patricia_Alejandra/Modelos_Pedag ogicos_Educacao_Distancia/Liberado/cap_01.pdf

Braga I. Realidade Aumentada em Museus: As Batalhas do Museu Nacional de Belas Artes,

RJ. Tese de doutorado em Engenharia de Sistemas Computacionais. Universidade Federal do Rio de Janeiro, 2007. XIII, pp. 153.

Costa R. C.; Vidal L. A. Experimentando um Ambiente Virtual com Pacientes Neuropsiquiátricos. Comunicação apresentada na II Conferência Internacional. Challenges, 2001.

Lévy, P.. As tecnologias da inteligência: o futuro do pensamento na era da informática. RJ: Editora 34, 1996.

Lima A. J.; Haguenauer C.; Cunha G.. A Realidade Aumentada no Ensino de Geometria Descritiva. GRAPHICA, Curitiba, 2007.

Kirner Claudio; Siscouto Robson. Realidade Virtual e Aumentada: Conceitos, Projeto e Aplicações. Livro do Pré-Simpósio IX Symposium on Virtual and Augmented Reality. Petrópolis - RJ, May, 2007.

Neves R.; Damiani M. Vygotsky e as teorias da aprendizagem. UNIrevista - Vol. 1, No. 2, April, 2006.

Santos A. Complexity and transdisciplinarity in education: five principles for rescuing the lost link. Rev. Bras. Educ. vol.13, No. 37, 2008.

Sawant N. The Tele-Immersive Data Explorer (TIDE): A Distributed Architecture for Teleimmersive Scientific Visualization, Master of Science in Electrical Engineering and Computer Science, Graduate College, University of Illinois at Chicago, 2000.

Treviranus, J. Adding Feeling, Sound and Equal Access to Distance Education. Adaptative Technology Resource Centre. University of Toronto, 2004.

Vilela I. O. Uma Arquitetura Multiagente do Comportamento de Personagens Virtuais. Tese de Doutorado em Engenharia de Sistemas Computacionais. Universidade Federal do Rio de Janeiro, COPPE. 2006, 221 pp. 
Young J. Virtual Reality on a Desktop Hailed as New Tool in Distance Education. Information Technology, 2000. Available from [ http://chronicle.com/free/v47/i06/06a04301.htm]. 